\title{
LÄBIRÄÄKIMISTE MODELLEERIMINE ARVUTIL
}

\section{Mare Koit}

Ülevaade. Artiklis käsitletakse dialooge, kus osalejad esitavad läbirääkimiste käigus argumente selle poolt ja vastu, et üks neist teeks või jätaks tegemata teatava tegevuse. Kui osalejatel on üks ja sama eesmärk, siis otsivad nad ühiselt argumente, mis näitaksid, mida positiivset toob kaasa tegevuse tegemine või vastavalt mittetegemine ja kuidas kõrvaldada võimalikud takistused eesmärgi saavutamisel. Kui osalejate eesmärgid on teineteisele vastupidised, siis peab vähemalt üks neist argumentide ja vastuargumentide esiletoomise järel oma algsest eesmärgist loobuma. Artiklis arendatakse dialoogimudelit, mille koosseisu kuulub argumendimudel. Tuuakse näiteid dialoogikorpuse analüüsist, et anda esialgne hinnang mudeli sobivusele inimestevaheliste argumenteerimisdialoogide analüusimiseks. Mudeli piiratud versioon on rakendatud arvutil, täielik realisatsioon on kavandatud edaspidiseks. *

Võtmesõnad: läbirääkimised, argument, dialoogimudel, teadmuse esitus, dialoogikorpus, eesti keel

\section{Sissejuhatus}

Läbirääkimised on selline suhtlemise vorm, kus osalejate grupp, keda ühendab soov koopereeruda, püüab jõuda ühiselt aktsepteeritava kokkuleppeni (vrd Rahwan jt 2004). Suhtlejad esitavad argumente oma seisukohtade toetuseks ja vajadusel partnerite omade ümberlükkamiseks. Suhtlemisel võivad, aga ei tarvitse eristuda selgelt fikseeritud pooled erinevate eesmärkidega. On võimalik, et ühel poolel õnnestub oma eesmärk vastaspoolele peale suruda. Samas võib kumbki pool jääda oma esialgse eesmärgi juurde ja läbirääkimised lõpevad kokkulepet saavutamata. Samuti võivad osalejad suhtluse käigus oma eesmärke modifitseerida ja neid teistele lähendada.

Paljud uurijad on modelleerinud läbirääkimisi arvutil.

Dung (1995) vaatleb argumenteerimissüsteemi kui paari <A, R >, kus A on (lõplik) argumentide hulk ja $\mathrm{R}$ on $\mathrm{nn}$ rünnaku relatsioon argumentide vahel $(\mathrm{R} \subseteq \mathrm{A} \times \mathrm{A})$.

* Artikli valmimist on toetanud Euroopa Regionaalarengufond Eesti Arvutiteaduse Tippkeskuse kaudu ning Eesti Teadusagentuur (projektid IUT20-56 "Eesti keele arvutimudelid", ETF9124 “Suhtlusagendi modelleerimine ja Eesti dialoogikorpus" ja ETF8558 “Eestikeelse spontaanse dialoogi struktuuri loomise keelelised vahendid"). 
Wagner (1998) käsitleb argumenteerimisel kasutatavaid mõisteid ja defineerib argumendi väite $\mathrm{G}$ kasuks kujul

$$
<\left\{\mathrm{f}_{1}, \ldots, \mathrm{f}_{\mathrm{m}}\right\},<\mathrm{r}_{1}, \ldots, \mathrm{r}_{\mathrm{n}}>>,
$$

kus $\left\{f_{1}, \ldots, f_{m}\right\}$ on $n n$ baasväidete ehk faktide hulk ja $r_{1}, \ldots, r_{n}$ reeglite järjend. Sealjuures on $r_{n} n n$ tippreegel, millest järeldub väide $G$. Wagner vaatleb tehisagente kui üleminekute süsteeme, mis osalevad läbirääkimistes ja debattides.

Rahwan jt (2004) käsitlevad kolme viisi läbirääkimiste formaliseerimiseks: mänguteoreetilist, heuristilist ja argumendipõhist. Neist esimene, nn dialoogimäng, modelleerib reeglite abil vestlust, kus kaks osalejat võtavad ühise eesmärgi nimel vaheldumisi voore ja esitavad argumente (Yuan jt 2008, Caelen, Xuereb 2011). Klassikalisel mänguteoreetilisel lähenemisel on aga tõsiseid arvutuslikke piiranguid, mis tegelikes rakendustes ei tarvitse kehtida, nt eeldus, et agentide ressursid on piiramatud ja et olekute ruum, kus sooritatakse otsing, on täielikult teada. Heuristilise lähenemisviisi puhul otsitakse lähendusi otsustustele, mida vestluses osalevad agendid vastu võtavad. Heuristilised mudelid kasutavad aga üksnes ligikaudset ratsionaalsuse mõistet, ei uuri läbi kogu võimalike olekute ruumi ja annavad seetõttu sageli lahendeid, mis pole optimaalsed (Rahwan jt 2004). Mõlemal juhul - nii mänguteoreetilise kui ka heuristilise lähenemise korral - eeldatakse, et agentide eelistused on fikseeritud. Kumbki agent ei saa otseselt mõjutada teise agendi eelistusi ega sisemisi mentaalseid hoiakuid (arvamusi, soove, eesmärke jms), mis moodustavad tema eelistuste mudeli. Ratsionaalne agent üksnes modifitseerib oma eelistuste mudelit saadud uue info põhjal. ${ }^{1}$

Argumendipõhise lähenemise korral võivad agendid läbirääkimiste protsessis põhjendada oma arvamusi ja muid mentaalseid hoiakuid. Argumenti käsitletakse läbirääkimistes kui infohulka, mis võimaldab agendil: a) tunnistada oma seisundit või b) mõjutada teise agendi seisundit (Jennings jt 1998). Seega võib agent lisaks ettepaneku aktsepteerimisele või tagasilükkamisele seda kritiseerida.

Besnard ja Hunter (2008) formaliseerivad argumenteerimist klassikalise loogika abil ja defineerivad argumendi kui paari $\langle\Phi, \alpha\rangle$, kus $\Phi$ on selline valemite hulk (teadmusbaasi alamhulk) ja a on selline valem, et

1. $\Phi$ ei ole vasturääkiv,

2. $\Phi$ implitseerib $\alpha$,

3. $\Phi$ on teadmusbaasi minimaalne alamhulk, mis rahuldab 2.

Öeldakse, et $\alpha$ on väide (ingl claim), $<\Phi, \alpha>$ on argument väite $\alpha$ toetuseks ja $\Phi$ on väite $\alpha$ toetus (ingl support).

Rahwan ja Larson (2011) uurivad loogilise tuletamise protseduuride kavandamise ja formaalse loogika seost juhul, kui teadmus on jagatud mitme osaleja vahel.

Hadjinikolis jt (2012) esitavad veenmisdialoogide argumenteerimispõhise raamistiku, kus agendid osalevad erilises dialoogimängus, esitades argumente ja kasutades ka partneri mudelit.

Kogu valdkonnast annavad ülevaate nt Chesñevar jt (2000), Prakken ja Vreeswijk (2002), Besnard ja Hunter (2008).

\footnotetext{
1 Uue lähenemise dialoogi modelleerimisele võib pakkuda uut tüüpi mänguteooria - lingvistiline geomeetria (LG). LG kasutab formaalsete keelte hierarhiat mängustrateegiate ja geomeetriat olekute ruumi esitamiseks (Stilman 2011, Stilman jt 2010). Mängija järgmise käigu otsing olekute ruumis asendatakse strateegia konstrueerimisega. Olekute ruum jaotatakse alamruumideks, konstrueeritakse mängijate võimalike strateegiate hulgad ja jäetakse kõrvale need strateegiad, mida ei saa rakendada. Alles jäänud strateegiatest konstrueeritakse probleemi optimaalne lahend. LG abil on modelleeritud mitmeid keerulisi probleeme, mida tavaliste arvutusmeetoditega ei õnnestu inimeksperdi tasemel lahendada, sh malemäng, kübersõda jms. (Autor tänab anonüümset retsensenti viite eest LG-le.)
} 
Siinses artiklis uuritakse dialooge, kus osalejad $A$ ja $B$ peavad läbirääkimisi selle üle, kas üks neist $(B)$ peaks vastu võtma otsuse teha või tegemata jätta teatud tegevus $D$. Otsuse vastuvõtmisele eelneb arutlus, kus subjekt kaalub $D$ tegemise või tegematajätmise positiivseid ja negatiivseid aspekte. Mõlemal osalejal võib olla üks ja sama eesmärk, näiteks nii $A$ kui ka $B$ taotlevad, et $B$ teeks $D$. Sellisel juhul otsivad nad dialoogi käigus koos argumente selle otsuse toetuseks, sh viise võimalike $D$ tegemist takistavate asjaolude kõrvaldamiseks. Osalejatel võivad aga olla hoopis teineteist välistavad eesmärgid, nt $A$ taotleb, et $B$ teeks $D$, aga $B$ tahaks $D$ tegemata jätta. Sellisel juhul püüab $A$ suhtluse käigus mõjutada $B$ arutlusprotsessi nii, et $B$ otsustaks siiski teha $D$. Ainus viis partnerit suhtluses mõjutada on esitada argumente, mis näitavad, millised meeldivad, kasulikud jms positiivsed aspektid on $D$ tegemisel $B$ jaoks ning et need kaaluvad üles $D$ tegemise võimalikud negatiivsed aspektid.

Varem on välja töötatud dialoogimudel, mille koosseisu kuulub arutlusmudel (Koit, Õim 2014a, Koit 2010). Käesolevas artiklis arendatakse seda mudelit edasi ja esitatakse läbirääkimiste formaalne mudel, kus osalejad toovad vaheldumisi esile argumente $D$ tegemise poolt ja vastu. Samuti võivad nad esitada teineteisele küsimusi, selleks et teha valikuid võimalike argumentide vahel ja tõrjuda partneri vastuargumente.

Artikli ülesehitus on järgmine: 2. osa on pühendatud läbirääkimiste mudelile; 3. osas tutvustatakse inimestevaheliste läbirääkimisdialoogide analüüsi tulemusi; 4. osas arutletakse mudeli sobivuse üle läbirääkimiste või vaidluse modelleerimiseks ja argumendi kirjeldamiseks; 5. osas tehakse kokkuvõtteid.

\section{Läbirääkimiste koostisosad}

Siin tutvustatakse dialoogimudelit ja rakendatakse seda läbirääkimistele, kus leiab muuhulgas aset argumentide edastamine ühelt osalejalt teisele.

\subsection{Dialoogimudel}

Vaatleme dialoogi loomulikus keeles kahe osaleja $A$ ja $B$ (inimese või tehisagendi) vahel (vt Koit, Õim 2014a). Olgu dialoogi algataja $A$ ja tema suhtluseesmärk mõjutada partnerit $B$ nii, et emba-kumba: kas $B$ otsustab teha tegevuse $D$ või $B$ otsustab mitte teha tegevust $D$.

$B$ suhtluseesmärk võib olla seesama mis osalejal $A$ või hoopis sellele vastupidine. Suhtluses püüab $A$ mõjutada partnerit $B$ nii, et too võtaks tegevuse $D$ suhtes vastu just sellise otsuse, mis vastab $A$ suhtluseesmärgile. Võimalikud on järgmised juhtumid:

(1) $A$ suhtluseesmärk on " $B$ teeb $D$ " ja $B$ eesmärk on " $B$ teeb $D$ ";

(2) $A$ eesmärk on " $B$ teeb $D$ " ja $B$ eesmärk on " $B$ ei tee $D$ ";

(3) $A$ eesmärk on " $B$ ei tee $D$ " ja $B$ eesmärk on " $B$ teeb $D$ ";

(4) $A$ eesmärk on " $B$ ei tee $D$ ” ja $B$ eesmärk on " $B$ ei tee $D$ ". 
Juhtumitel (1) ja (4) on $A$ ja $B$ suhtluseesmärk üks ja seesama ning nad otsivad vestluse käigus üheskoos põhjendusi (argumente), miks teha (vastavalt mitte teha) $D$ ja kuidas ületada võimalikke takistusi $D$ tegemise ees või, vastupidi, vältida võimalikke ebasoovitavaid tagajärgi, mida $D$ tegematajätmine võib kaasa tuua.

Juhtumitel (2) ja (3) on $A$ ja $B$ eesmärgid teineteist välistavad, initsiaator $A$ esitab argumente, mis peaksid mõjutama partnerit $B$ aktsepteerima $A$ eesmärki ja loobuma omaenese algsest eesmärgist. Samas võib $B$ esitada vastuargumente, mis peaksid sundima hoopis partnerit $A$ aktsepteerima $B$ eesmärki ja loobuma oma algsest eesmärgist.

$A$ käsutuses on partneri mudel - tema ettekujutus $B$ kohta, mis annab talle alust arvata, et $B$ soostub võtma omaks $A$ suhtluseesmärgi. Konstrueerides oma esimest vooru, peab $A$ planeerima dialoogiaktid (nt ettepanek, soov, küsimus, ettepanek koos argumendiga jne, sõltuvalt oma ettekujutusest $B$ kohta) ja määrama nende verbaalse vormi (st lausungid). Partner $B$ interpreteerib $A$ vooru ja enne kui anda vastus, käivitab oma peas arutlusprotseduuri, et võtta vastu otsus - teha või mitte teha $D$. Siis planeerib ta dialoogiaktid (nt nõustumine, keeldumine, keeldumine koos argumendiga jne) ja nende verbaalse vormi, selleks et teatada partnerile oma otsusest. Kui $B$ vastus on keeldumine, siis peab $A$ muutma olemasolevat partneri mudelit (see ei vastanud tegelikkusele, sest $A$ eeldas, et $B$ nõustub omaks võtma $A$ eesmärki) ja leidma uusi argumente, et panna $B$ siiski vastu võtma taotletavat otsust.

$B$ võib oma keeldumisele lisada argumente. Need (vastu-)argumendid annavad $A$-le infot $B$ peas toimunud arutlusprotsessi kohta, mis lõppesid negatiivse otsusega.

\subsubsection{Arutlusmudel}

Siin kasutatavat arutlusmudelit on detailselt kirjeldatud artiklis (Koit, Õim 2014a). Üldjoontes järgib see ideid, mis on realiseeritud BDI (ingl belief-desire-intention) mudelis, kuid tal on spetsiifiline iseärasus - modelleeritakse nn "naiivset" arutlusteooriat, mida inimesed kasutavad igapäevaelus, kui nad suhtlevad teiste inimestega ning püüavad prognoosida ja mõjutada nende otsuseid.

Arutlusmudel koosneb kahest osast: 1) inimese motivatsioonisfääri mudelist ja 2) arutlusprotseduuridest. Motivatsioonisfääris saab esile tuua põhilised tegurid, mis reguleerivad subjekti arutlust teatava tegevuse $D$ kohta. Juhul kui subjekt arutleb selle üle, kas teha tegevus $D$, siis, esiteks, võib subjektil olla soov teha $D$, kui selle tegevuse meeldivad aspektid ületavad ebameeldivaid; teiseks, tal võib olla vaja teha $D$, kui see on kasulik mingi kõrgema eesmärgi saavutamiseks ja $D$ tegemise kasulikud aspektid ületavad kahjulikke; kolmandaks, arutlev subjekt võib olla olukorras, kus ta peab (on kohustatud) tegema $D$ - kui tegematajätmine toob kaasa karistuse. Neid tegureid nimetatakse mudelis vastavalt SOOV-, VAJA- ja PEAB-determinantideks.

Kui subjekt arutleb selle üle, miks mitte teha $D$, siis on arutlust käivitavad põhifaktorid analoogilised: esiteks, subjekt ei soovi teha $D$, kui $D$ ebameeldivad aspektid kaaluvad üles meeldivad; teiseks, tal pole vaja teha $D$, kui $D$ kahjulikud aspektid ületavad kasulikke; ning kolmandaks, $D$ tegemine on talle keelatud (ei ole lubatud), tuues kaasa teatava karistuse. Neid faktoreid nimetatakse vastavalt POLE-SOOVI-, POLE-VAJA- ja POLE-LUBATUD-determinantideks. 
Siinses arutlusmudelis esitatakse subjekti motivatsioonisfääri mudel vektorina, mille komponentidel on arvulised väärtused, nn kaalud: $\mathrm{w}=$ (w(ressursid), w(meeldiv), w(ebameeldiv), w(kasulik), w(kahjulik), w(kohustuslik), w(keelatud), $\mathrm{w}($ karistus-teha), w(karistus-mitte-teha)). Seejuures $\mathrm{w}($ ressursid $)=1$, kui subjektil on olemas kõik $D$ tegemiseks vajalikud ressursid (vastasel korral o); $\mathrm{w}($ kohustuslik) $=1$, kui $D$ on kohustuslik (muidu 0 ); w(keelatud) $=1$, kui $D$ on keelatud (muidu o). Edasi, w(meeldiv) jne tähistavad $D$ meeldivate jne aspektide kaalu; w(karistus-teha) - keelatud tegevuse $D$ tegemisele järgnevat karistuse suurust ja w(karistus-mitte-teha) - kohustusliku $D$ tegematajätmisele järgnevat karistuse suurust. Nende aspektide kaalud on mittenegatiivsed täisarvud.

Arutlusmudeli teine osa koosneb arutlusprotseduuridest, mis eeldatavasti reguleerivad inimese arutelusid tegevuste kohta. Iga arutlusprotseduur koosneb sammudest, mida subjekt läbib oma arutlusprotsessis; igal sammul arvutab ja võrdleb ta $D$ erinevate aspektide summaarseid kaale ning tulemuseks on otsus: teha või mitte teha $D$.

Iga arutlusprotseduur sõltub determinandist, mis selle käivitab (siinses mudelis on nendeks SOOV, VAJA ja PEAB või vastavalt POLE-SOOVI, POLE-VAJA, POLELUBATUD). Esitatagu siin näitena arutlusprotseduur, mille käivitab determinant POLE-VAJA, st $D$ tegemine ei ole arutlevale subjektile kasulik.

Eeltingimus: w(kasulik) < w(kahjulik).

1) Kas D tegemiseks on piisavalt ressursse? Kui ei, siis 9.

2) Kas w(kasulik) < w(ebameeldiv) + w(kahjulik)? Kui jah, siis 9.

3) Kas D on kohustuslik? Kui ei, siis 5 .

4) Kas w(kasulik) + w(karistus-mitte-teha $)<\mathrm{w}($ ebameeldiv $)+\mathrm{w}($ kahjulik $)$ ? Kui jah, siis 9. Kui ei, siis 8.

5) Kas D on keelatud? Kui jah, siis 9.

6) Kas w(kasulik) < w(ebameeldiv $)+w($ kahjulik $)+w($ karistus-teha $)$ ? Kui jah, siis 9.

7) Kas w(meeldiv $)+\mathrm{w}($ kasulik $)<\mathrm{w}($ ebameeldiv $)+\mathrm{w}($ kahjulik $)+\mathrm{w}($ karistusteha)? Kui jah, siis 9.

8) Otsus: teha $D$. Lõpp.

9) Otsus: mitte teha $D$.

Mudelis kasutatakse kahte kaalude vektorit. Vektor $\mathrm{w}^{\mathrm{AB}}$ ( $A$ arvamused $B$ hinnangute kohta tegevusele $D$, kus $B$ tähistab suhtluspartnerit) kujutab endast partneri mudelit ning vektor $\mathrm{w}^{\mathrm{B}}$, kus komponentide väärtused on $B$ tegelikud hinnangud $D$ aspektidele (mille täpseid väärtusi $A$ ei tea), on $B$ iseenda mudel.

\subsubsection{Suhtlusstrateegiad ja -taktikad}

Suhtlusstrateegia all mõistetakse siin algoritmi, mida suhtluses osaleja kasutab oma suhtluseesmärgi saavutamiseks. Suhtluse algataja $(A)$ võib realiseerida oma suhtlusstrateegiat erinevatel viisidel: rõhutada $D$ meeldivust või vastavalt ebameeldivust (st ahvatleda partnerit $B$ tegevust tegema või vastavalt tegemata jätma), rõhutada $D$ kasulikkust või vastavalt kahjulikkust $B$ jaoks (st veenda partnerit), rõhutada karistust, mis järgneb kohustusliku $D$ tegematajätmisele või vastavalt keelatud tegevuse tegemisele (ähvardada) jne. Neid suhtlusstrateegia realiseerimise konkreetseid 
viise nimetatakse suhtlustaktikateks. Osaleja $A$, püüdes suunata partneri $B$ arutlust soovitava otsuse poole (tegema või vastavalt mitte tegema $D$ ), esitab argumente $D$ tegemise (mittetegemise) poolt, aga $B$, kui ta vaidleb vastu, esitab vastuargumente.

Taotledes $B$ otsust teha $D$, võib $A$ rõhutada

- $\quad D$ meeldivust (st püüda käivitada partneris arutlusprotseduuri determinandiga SOOV),

- $\quad$ D kasulikkust (käivitada arutlusprotseduuri determinandiga VAJA),

- (kohustusliku) D tegematajätmisele järgnevat karistust (käivitada arutlusprotseduuri determinandiga $\mathrm{PEAB}$ ).

Saavutamaks $B$ otsust mitte teha $D$, võib $A$ rõhutada

- $\quad D$ ebameeldivust (käivitamaks arutlusprotseduuri determinandiga POLE-SOOVI),

- $\quad$ kahjulikkust (käivitamaks arutlusprotseduuri determinandiga POLE-VAJA),

- $\quad$ (keelatud) $D$ tegemisele järgnevat karistust (käivitamaks arutlusprotseduuri determinandiga POLE-LUBATUD).

Kui $A$ ja $B$ suhtluseesmärgid on vastandlikud, siis lihtsaim taktika, mida $A$ saab kasutada, on nn kaitse: suhtluse algataja $A$ on loovutanud initsiatiivi ega rõhuta ühtegi $D$ positiivset (vastavalt negatiivset) aspekti, vaid ainult tõrjub $B$ võimalikke vastuargumente. $B$ jaoks on lihtsaim taktika tõrkumine: keeldumine omaks võtmast $A$ eesmärki, ühtegi argumenti lisamata.

Igal suhtlustaktikal, mida $A$ saab rakendada, on oma "nimiaspekt”, milleks on vastavalt meeldivus tegevuse tegemisele või ebameeldivus tegevuse tegematajätmisele ahvatlemise korral, kasulikkus tegevuse tegemisele või kahjulikkus tegevuse tegematajätmisele veenmise korral ja keelatud $D$ tegemisele või kohustusliku $D$ tegematajätmisele järgnev karistus ähvardamise korral. A püüab esitada argumente, rõhutades oma valitud taktika nimiaspekti (see on kooskõlas arutlusprotseduuriga, mida $A$ püüab $B$ peas käivitada).

\subsubsection{Teadmusbaas}

Osaleja (agendi) $A$ teadmusbaas sisaldab 1) arutlusalgoritmid, 2) suhtlusstrateegiad ja -taktikad, 3) partneri mudeli $\mathrm{w}^{\mathrm{AB}}$, 4) dialoogiaktide nimestiku, mida $A$ saab kasutada (ettepanek, küsimus, väide jne), 5) lausungite nimestiku, mida $A$ saab kasutada dialoogiaktide verbaliseerimiseks. Siin eeldatakse lihtsuse mõttes, et kumbki suhtluses osaleja kasutab lõplikku hulka etteantud lauseid. Lauseid ei analüüsita morfoloogiliselt ega süntaktiliselt; semantiline analüüs ja genereerimine on lihtsustatud sel viisil, et need laused on eelnevalt klassifitseeritud. Näiteks on olemas laused partnerile suhtluseesmärgi teatamiseks (Lähme kinno), laused tegevuse meeldivate, ebameeldivate jne aspektide rõhutamiseks (Film on põnev; Kinopilet on odav jne), nõustuvad laused (Olen nõus) jne. Igal sellisel lausel on (kasutatavas mudelis numbriline) kaal - mõned laused "kaaluvad" rohkem kui teised. Kaalud sõltuvad nii tegevusest kui ka suhtluses osalejatest. Näiteks lausel Peole tuleb kümme külalist, mida $A$ kasutab tegevuse $D$ meeldivuse rõhutamiseks, võib ühe suhtluspartneri jaoks olla kaal 10 ja teise jaoks 1. 
$B$ teadmusbaasis sisalduvad analoogilised teadmised, välja arvatud see, et partneri mudeli $\mathrm{w}^{\mathrm{AB}}$ asemel on iseenda mudel $\mathrm{w}^{\mathrm{B}}$.

Siin eeldatakse, et iga lausungit saab kasutada ainult ühe korra. Seega, kui $A$ rakendab näiteks tegevuse tegemisele ahvatlemise taktikat ja tema käsutuses ei ole enam lauseid $D$ meeldivuse rõhutamiseks (mis on ahvatlemise nimiaspekt), siis peab $A$ valima ahvatlemise asemel uue taktika või loobuma oma suhtluseesmärgist.

\subsubsection{Argumendi struktuur}

Pidades läbirääkimisi tegevuse tegemise või mittetegemise üle, edastavad $A$ ja $B$ teineteisele oma argumente. Osaleja $A$ argumendi üldine struktuur on järgmine (vrd Besnard, Hunter 2008, Koit, Õim 2014b):

$$
<\left\{\mathrm{R}, \mathrm{T}, \mathrm{w}^{\mathrm{AB}} \text { i, fakt }{ }^{\mathrm{A}}\right\}, \text { eesmärk }^{\mathrm{A}}>,
$$

kus

- $\quad \mathrm{R}$ on arutlusprotseduur, mida $A$ üritab käivitada partneris $B$,

- T on kasutatav suhtlustaktika,

- $\quad \mathrm{w}^{\mathrm{AB}}{ }_{\mathrm{i}}=\left(\mathrm{w}^{\mathrm{AB}}{ }_{\mathrm{i}}\right.$ (ressursid), $\mathrm{w}^{\mathrm{AB}}{ }_{\mathrm{i}}$ (meeldiv), $\mathrm{w}^{\mathrm{AB}}{ }_{\mathrm{i}}$ (ebameeldiv), $\mathrm{w}^{\mathrm{AB}}{ }_{\mathrm{i}}($ kasulik $)$, $\mathrm{w}^{\mathrm{AB}}{ }_{\mathrm{i}}$ (kahjulik), $\mathrm{w}^{\mathrm{AB}}{ }_{\mathrm{i}}$ (kohustuslik), $\mathrm{w}^{\mathrm{AB}}{ }_{\mathrm{i}}$ (keelatud), $\mathrm{w}^{\mathrm{AB}}{ }_{\mathrm{i}}$ (karistus-teha), $\mathrm{W}^{\mathrm{AB}}{ }_{\mathrm{i}}$ (karistus-mitte-teha)) on jooksev partneri mudel (ajahetkel i),

- $\quad$ fakt $^{\mathrm{A}}$ tähistab $A$ valitud lauset partneri mudelis esinevate kaalude mõjutamiseks, pärast mida annab arutlusprotseduur $\mathrm{R}$ muudetud mudelil eeldatavasti $B$ positiivse otsuse (kooskõlas $A$ eesmärgiga); tema kaal on $\mathrm{w}\left(\right.$ fakt $\left.^{\mathrm{A}}\right)$,

- $\quad$ eesmärk ${ }^{\mathrm{A}}=$ “ $B$ teeb $D$ ” (või vastavalt “ $B$ ei tee $D$ ”).

Argumendi koosseisu võib kuuluda ka mitu erinevat fakti/lauset (mitte ainult üksainus).

Siin eeldatakse, et võimalikud laused (lausungid) on jagatud klassidesse, nt $\mathrm{P}_{\text {on_ressursid }}$ tähistab lausete hulka, mida $A$ saab kasutada, näitamaks partnerile $B$, et $D$ tegemiseks leiduvad ressursid; $\mathrm{P}_{\text {suurenda_meeldivust }}$ tähistab lausete hulka $D$ meeldivuse suurendamiseks jne.

Suhtluses $A$ esiletoodud fakt $\mathrm{A}^{\mathrm{A}}$ "toodab" uue partneri mudeli $\mathrm{w}^{\mathrm{AB}}{ }_{\mathrm{i}+1}$ (järgmisel ajahetkel $\mathrm{i}+1)$ :

kui fakt ${ }^{\mathrm{A}} \in \mathrm{P}_{\text {on_ressursid, }}$, siis $\mathrm{w}^{\mathrm{AB}}{ }_{\mathrm{i}+1}$ (ressursid): $=1$;

kui fakt ${ }^{\mathrm{A}} \in \mathrm{P}_{\text {puuduvad_ressursid, }}$ siis $\mathrm{W}^{\mathrm{AB}}{ }_{\mathrm{i}+1}($ ressursid $):=0$;

kui fakt ${ }^{\mathrm{A}} \in \mathrm{P}_{\text {suurenda_meeldivust, }}$, siis $\mathrm{w}^{\mathrm{AB}}{ }_{\mathrm{i}+1}$ (meeldivus): $=\mathrm{w}^{\mathrm{AB}}{ }_{\mathrm{i}}$ (meeldivus) $+\mathrm{w}\left(\right.$ fakt ${ }^{\mathrm{A}}$ ) jne.

Partneri $B$ (vastu-)argument on analoogilisel kujul:

$$
<\left\{\mathrm{R}^{\mathrm{B}}, \mathrm{T}^{\mathrm{B}}, \mathrm{w}^{\mathrm{B}}, \text { fakt }^{\mathrm{B}}\right\}, \text { eesmärk } \mathrm{B}^{\mathrm{B}}>,
$$

kus arutlusalgoritm $\mathrm{R}^{\mathrm{B}}$ toodab mudelil $\mathrm{w}^{\mathrm{B}}$ otsuse " $B$ teeb $D$ ” või vastavalt " $B$ ei tee $D$ ” (s.o eesmärk ${ }^{\mathrm{B}}$ ), fakt ${ }^{\mathrm{B}}$ näitab $D$ aspekti, mille (liiga väike või liiga suur) väärtus põhjustab selle otsuse, ja $\mathrm{T}^{\mathrm{B}}$ on $B$ jooksev suhtlustaktika. Siin eeldatakse, et $B$ iseenda mudel $\mathrm{w}^{\mathrm{B}}$ ei muutu, st ainult $A$ saab suhtluse käigus järk-järgult lähendada oma ettekujutust partnerist tegelikkusele. 
Partneri $B$ fakt $^{\mathrm{B}}$ annab osalejale $A$ infot tema järgmise lause/fakti valimiseks suhtluses. Näiteks kui $A$ suhtluseesmärk on “ $B$ teeb $D$ ” ja fakt ${ }^{\mathrm{B}} \in \mathrm{P}_{\text {puuduvad_ressursid, }}$, siis on $\mathrm{w}^{\mathrm{AB}}{ }_{\mathrm{i}}$ (ressursid) tegelik väärtus o ning $A$ peab oma järgmise lause valima hulgast $\mathrm{P}_{\text {on_ressursid }}$ (pärast seda lauset kehtib eeldatavasti $\mathrm{w}^{\mathrm{AB}}{ }_{\mathrm{i}+1}($ ressursid $)=1$ ) ja järgmine lause tuleb valida arutlusprotseduuri $\mathrm{R}$ nimiaspekti väärtust suurendavate lausete hulgast, mida $A$ üritab käivitada partneris $B$, kasutades suhtlustaktikat T. Teisiti öeldes, $A$ reageerib küll $B$ toodud vastuargumendile (tõrjudes seda), aga samas jätkab ka oma valitud taktikat $\mathrm{T}$, esitades järgmise fakti, mis rõhutab T nimiaspekti.

Kuidas valib partner $B$ oma järgmise lause/fakti? Ta käivitab parajasti kehtiva arutlusprotseduuri $\mathrm{R}^{\mathrm{B}}$ oma mudelil $\mathrm{w}^{\mathrm{B}}$. (Nii see arutlusprotseduur kui ka $B$ iseenda mudel võivad muidugi erineda $A$ kasutatavast arutlusprotseduurist $\mathrm{R}$ ja partneri mudelist $\mathrm{w}^{\mathrm{AB}}$.) $B$ rakendab oma arutlusprotseduuri ja selle tulemusel saab ta määrata $D$ aspekti, mille väärtus põhjustas tema (negatiivse) otsuse. Näiteks võib ta valida lause, mis väljendab, et $D$ on ebameeldiv: [Ma ei tule kinno, sest] mulle ei meeldi põnevusfilmid, aga ta võib ka lihtsalt teatada: Ma ei tule kinno. Viimasel juhul ei saa $A$ rünnata ühtki vastuargumenti, tal ei jää üle muud, kui valida järjekordne lause jooksva suhtlustaktika T nimiaspekti väärtust suurendavate lausete hulgast, lootuses, et see muudab partneri mudelit positiivse otsuse saavutamiseks vajalikul määral.

Kui $A$ käsutuses ei ole rohkem lauseid T nimiaspekti väärtuse suurendamiseks, siis ta kas 1) valib $B$ mõjutamiseks uue suhtlustaktika ja sellele vastava arutlusalgoritmi või 2) loobub oma suhtluseesmärgist.

\subsection{Läbirääkimiste struktuur}

Kui $A$ ja $B$ suhtluseesmärgid on vastandlikud, siis alustavad nad debatti ehk vaidlust (nt $A$ suhtluseesmärk on " $B$ teeb $D$ ”, aga $B$ eesmärk on “ $B$ ei tee $D$ ”). Üks osaleja saavutab vaidluse tulemusel oma suhtluseesmärgi ("võidab"), teine aga peab oma eesmärgist loobuma ("kaotab").

Kui $A$ ja $B$ suhtluseesmärgid ühtivad, siis otsivad nad kooperatiivses suhtluses üheskoos argumente, mis toetaksid selle ühise eesmärgi saavutamist. Suhtluses võib emb-kumb neist, näiteks $B$, viidata takistustele eesmärgi saavutamisel. Siis peab $A$ leidma argumente, näitamaks, kuidas neid takistusi saab kõrvaldada. Läbirääkimiste lõpptulemuseks on kas eesmärgi saavutamine (mõlemad osalejad "võidavad") või sellest loobumine, kui teatavaid takistusi ei õnnestu kõrvaldada (mõlemad osalejad "kaotavad").

Praeguses mudelis ei ole ette nähtud suhtluseesmärgi modifitseerimist, st otsus on kas $B$ teeb $D$ või $B$ ei tee $D$ (välistatud on näiteks $D$ tegemine või tegematajätmine teatud tingimustel). Siiski võivad osalejad lõpetada läbirääkimised ka kokkuleppega, et otsustamine lükatakse edasi kuni järgmiste läbirääkimisteni.

Siin eeldatakse, et $A$ ja $B$ arutlusalgoritmide hulk on ühine. Samuti eeldatakse, et $A$ ja $B$ saavad mõlemad kasutada fikseeritud hulka dialoogiakte ja vastavaid lauseid, mis on liigitatud semantiliselt, nagu eespool juba mainitud.

Alustades läbirääkimisi, fikseerib algataja $A$ (või moodustab oma eelteadmiste alusel) partneri mudeli $\mathrm{w}^{\mathrm{AB}}$ ja määrab suhtlustaktika $\mathrm{T}$, mida kasutada, st koos sellega määrab ta ka arutlusalgoritmi R, mida püüab käivitada $B$ peas. Partneril $B$ 
on olemas iseenda mudel $\mathrm{w}^{\mathrm{B}}$. Ta määrab arutlusprotseduuri $\mathrm{R}^{\mathrm{B}}$, mida tema kasutab, otsustamaks, kas teha $D$ või mitte, ja suhtlustaktika $\mathrm{T}^{\mathrm{B}}$ (näiteks püüda haarata initsiatiivi ja rünnata partneri argumente).

Läbirääkimiste üldine struktuur on järgmine (sulgudes olevad dialoogiaktid võivad puududa):

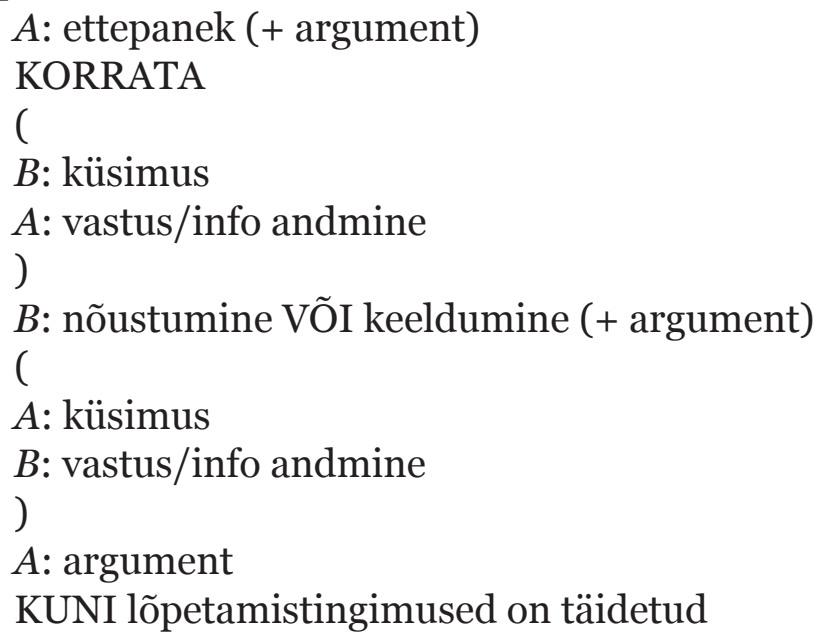

Mõlemad osalejad, nii $A$ kui ka $B$, võivad osutada, et lõpetamistingimused on täidetud: 1) suhtluseesmärk on saavutatud, 2) loobuda oma suhtluseesmärgist (anda alla), hoolimata sellest, et leidub veel lauseid/fakte uute argumentide väljendamiseks, 3) ei leidu enam lauseid fikseeritud suhtlustaktika jätkamiseks, aga ei valita uut taktikat, kuigi see oleks veel võimalik, 4) kõiki suhtlustaktikaid on juba proovitud ja kõik laused/faktid edastatud, kuid ometi ei ole õnnestunud saavutada suhtluseesmärki.

Osalejad võivad esitada suhtluse käigus teineteisele küsimusi, selleks et teha valikuid erinevate lausete vahel, mida nad saavad kasutada argumenteerimisel.

Arvutil on realiseeritud kirjeldatud mudeli erijuht - vaidlus, kus $A$ suhtluseesmärk on “ $B$ teeb $D$ ” ja $B$ eesmärk “ $B$ ei tee $D$ ” (Koit, Õim 2014a, 2014b, Koit 2012).

\section{Inimestevaheliste dialoogide analüüs}

Selleks et anda esialgne hinnang mudelile, võeti ette inimestevaheliste argumenteerimisdialoogide analüüs. Tartu Ülikooli eesti dialoogikorpuses leidub kolme liiki suulisi dialooge, kus esineb läbirääkimisi: müügivestlused ning mõned reisibüroodialoogid ja argivestlused (Hennoste jt 2009). Kõik dialoogid on salvestatud autentsetes olukordades ja litereeritud, kasutades vestlusanalüüsi transkriptsiooni. Käesoleva uurimuse jaoks analüüsiti 52 telefoni teel toimunud müügivestlust (neist 32 sisaldasid läbirääkimisi; ülejäänutes oli tegu kas soovitud isiku puudumisega, kõne katkemisega enne läbirääkimisteni jõudmist vms tõrkega), 44 argivestlust (pooled telefoni- ja pooled silmast-silma vestlused), kus leidus lõike, milles peeti läbirääkimisi mingi tegevuse üle, ning 28 reisibüroodialoogi (millest vaid viies vestluses argumenteeris ametnik teatud reisi kasuks; ülejäänud olid infodialoogid).

Järgnevas tuuakse kaks näidet eesti dialoogikorpusest. Esimene on katkend silmast-silma vestlusest reisibüroos ametniku $(A)$ ja kliendi $(B)$ vahel, kus kliendi eesmärk on reisida Hispaaniasse ja ametnik teeb temaga koostööd selle eesmärgi 
saavutamise nimel. Teine näide on ühe koolitusfirma (mille varjunimi on Tiritamm) esindaja ( $A$ ) telefonikõne, kes pakub koolituskursusi teise firma juhile ehk kliendile $(B)$.

(1) Ametnik põhjendab, miks pakutav reis on huvitav ja kasulik. Klient esitab lisaküsimuse.

/---/

A: siin on: ' paar sellist=õ (o.6) 'päris huvitavat prog' rammi.

fakt $^{\mathrm{A}}$

o.5) näiteks=õ (2.2) näiteks väga 'iseloomulik on Hispaaniale se 'Kordoba: (o.9) 'Kordoba ((Cordoba)) piirkond, (o.4) siin=on se=on 'keskajal keskaegne 'linn?

fakt ${ }^{\mathrm{A}}$

ja $=$ sis=õõ (0.5) seal on 'võimalik: ka seda (o.8) $\tilde{o}=$ ' härjavõitlust vaadata.

fakt $^{\mathbf{A}}{ }_{3}$

(.) et see ' etendus on=ka=nagu=juba seal hinna 'sees, (0.5) ja see maksab mingi 'kaheksasada 'kuus krooni.

fakt ${ }_{4}^{\mathrm{A}}$

(1.5)

$B$ : need võib kõik ['eraldi 'juurde] tellida.

küsimus

$A$ : 'jaa (.) jaa

(.) ja neid saab juba 'siit koha- 'siit broneerida.

vastus

/---/

(2) Siin toob klient $B$ mitmeid vastuargumente koolitusfirma esindaja $A$ pakutud kursustele. $A$ esitab küsimuse ja $B$ vastus võimaldab tal leida uue argumendi: ta osutab, et firma suudab siiski õpetada midagi kliendile vajalikku, vastupidiselt kliendi oletusele.

/---/

$B$ : 'teate mis 'te: te olete valesse f(h)irmasse $\$$ sattund. $\$$

\section{keeldumine}

.hhh põhjus on lihtsalt selles et minu mõlemad müüja=konsultandid nad 'väga hästi haritud.

fakt $^{\mathbf{B}_{1}}$

(0.2) nad 'on (0.4) \& eluaeg inimestega suheld 'kõrgetel kohtadel.

fakt $^{\mathbf{B}_{2}}$

.hhh mis 'minusse puutub (o.3) olen 'mina õppinud ära 'firma juhtimise \$ mul on 'topelt 'kõrgharidus. \$

fakt $_{3}{ }_{3}$

/---/

$A$ : .hhh et 'tehakse sisuliselt presentatsi' oo[ne kus siis=ee]

küsimus

$B:$ ['just 'nimelt.]

vastus

/---/

$A$ : .hhhh ?jaa?jaa. 
.h SEDA PAKUB KA 'TIRITAMM muidu 'välja: ee kuidas siis=õõ 'läbi [viia 'presentatsi' oone.]

\section{fakt $^{\mathrm{A}}$ \\ /---/}

Korpuse analüüs toetab arvamust, et toodud mudel on üldjoontes sobiv läbirääkimisdialoogi kirjeldamiseks. Seni on eesti dialoogikorpuse dialoogides märgendatud dialoogiaktid, kasutades Tartu Ülikoolis väljatöötatud dialoogiaktide tüpoloogiat (Hennoste jt 2009), ning spetsiaalse tarkvara abil määratud alamdialoogid ja suhtlusstrateegiad (Aller jt 2014), kuid ei ole lähemalt uuritud läbirääkimisdialoogide argumendistruktuuri. Reaalsed dialoogid ei ole muidugi "puhtad” läbirääkimised vaadeldava mudeli mõttes, vaid sisaldavad inimestevahelistele vestlustele omaseid kõrvalekaldumisi pealiinilt, nt ühe või teise osaleja algatatud parandussekventse.

\section{Arutelu}

Artiklis on vaatluse all dialoogid, kus osalejad $A$ ja $B$ toovad kordamööda esile argumente teatava tegevuse $D$ tegemise poolt ja vastu. Dialoogi algataja $A$ suhtluseesmärgiks on, et partner $B$ võtaks vastu teatava otsuse tegevuse $D$ tegemise kohta. Osalejate eesmärgid võivad olla omavahel vastuolus (nt $A$ eesmärk on, et $B$ teeks $D$, aga $B$ eesmärk on mitte teha $D$ ) või kooskõlas (nt nad taotlevad ühiselt $B$ otsust teha $D$, olgugi et $D$ tegemisel võib olla takistusi, mille kõrvaldamisvõimalusi nad otsivad läbirääkimiste käigus, esitades mitmesuguseid argumente, edastades ja kaitstes sellega oma seisukohti).

Artikli 2. osas esitati läbirääkimisdialoogi formaalne mudel. Peab rõhutama, et see mudel hõlmab üksnes teatud kitsalt piiritletud läbirääkimisi: kõne all on mingi tegevuse tegemine või tegematajätmine. Läbirääkimiste tulemuseks on $B$ otsus (jah või ei) tegevuse tegemise kohta. Kui $A$ ja $B$ on üksmeelsed, st nende algsed eesmärgid on samad, siis jõuavad nad läbirääkimiste lõpuks ühise kokkuleppeni. See ei tähenda tingimata, et nad saavutavad oma (ühise) suhtluseesmärgi. Näiteks võib juhtuda, et kuigi nii $A$ kui ka $B$ on püstitanud eesmärgi, et $B$ teeks $D$, selgub suhtluse käigus, et $B$ ressursid $D$ tegemiseks on puudulikud ja kumbki, ei $A$ ega $B$, ei suuda leida argumente, mis avaksid võimalusi ressursse juurde hankida. Sellisel juhul jõutakse küll ühise otsuseni (“ $B$ ei tee $D$ ”), kuid suhtluseesmärk jääb saavutamata. Mudel ei käsitle olukordi, kus algset suhtluseesmärki modifitseeritakse, näiteks seatakse $D$ tegemisele teatavad eeltingimused.

Kui $A$ ja $B$ alustavad vastandlike suhtluseesmärkidega, siis on tegu vaidlusega. Vaidlus lõpeb tavaliselt ühe osaleja "võidu" ja teise "kaotusega", st üks osaleja saavutab oma eesmärgi ja teine peab sellest loobuma. On ka võimalik, et n-ö "otsad jäävad lahtiseks”, st $B$ lükkab otsustamise edasi. Sellisel juhul ei ole vaidluses võitjat ega kaotajat. Mudel ei käsitle olukordi, kus läbirääkimiste käigus jõutakse kompromissini algsete eesmärkide vahel, st kus mõlemad pooled teevad järeleandmisi ja muudavad oma eesmärki.

Argumendi struktuur, mida mudelis kasutatakse, on samuti kohandatud kitsalt siin vaadeldavat liiki läbirääkimistele. Võttes eeskujuks Besnardi ja Hunteri (2008) pakutud esituse $<\Phi, \alpha>$, kus $\Phi$ on valemite hulk (teadmusbaasi alamhulk 
ehk eeldused) ja a on valem (väide, järeldus), on siin $\Phi$ rollis järgmine teadmiste hulk: suhtlustaktika, arutlusprotseduur ja tegevuse $D$ aspektide kaalud ( $A$ puhul oletatavad, $B$ puhul tegelikud), mis kehtivad argumendi esitamise hetkel, ning fakt või faktide hulk tegevuse $D$ teatud aspekti(de) kaalu(de) muutmiseks. Väite $\alpha$ rollis on argumendi autori suhtluseesmärk (mille toetuseks ta argumendi esitab). Suhtluses esitatakse argumendist ilmutatult üksnes fakt (või faktid), ülejäänud osad on varjatud (vt näited osas 3).

\section{Kokkuvõte}

Siin uuriti suhtlust, kus algataja $A$ suhtluseesmärk on, et partner $B$ võtaks vastu otsuse teatava tegevuse $D$ suhtes ("teha $D$ " või "mitte teha $D$ ”). $B$ eesmärk võib olla sama mis $A$ oma või vastupidine. Viimasel juhul alustavad $A$ ja $B$ vaidlust. Vaidluses püüab $A$ mõjutada $B$ arutlusprotsesse sellisel viisil, et $B$ loobuks oma algsest eesmärgist ja võtaks vastu otsuse, mis vastab $A$ suhtluseesmärgile (sellisel juhul $A$ võidab ja $B$ kaotab vaidluse). Kui $A$-l ei õnnestu suhtluses jõuda $B$ soovitava otsuseni, siis ta ei saavuta oma suhtluseesmärki ( $A$ kaotab ja $B$ võidab vaidluse).

Kui $A$ ja $B$ taotlevad ühte ja sedasama eesmärki, siis alustavad nad diskussiooni, et selgitada, kas $D$ tegemisel on takistusi või vastavalt $D$ mittetegemisel on ebasoovitavaid tagajärgi.

Artiklis esitati dialoogimudel, mis sisaldab ühe osana argumentide edastamise ühelt osalejalt teisele. Esitati argumendimudel, mis suhtluse algataja $A$ puhul sisaldab partneri $B$ mudeli (või $B$ puhul iseenda mudeli), arutlusprotseduuri, mida $A$ üritab käivitada $B$ peas (või vastavalt, mida $B$ ise rakendab), suhtlustaktika ja lausete/faktide hulga, mis kogumina peaksid $A$ ja/või $B$ tooma soovitava järelduseni. Järeldust (otsust $D$ tegemise kohta) tõlgendatakse argumendi struktuuris kui väidet (mis samas on argumendi autori suhtluseesmärk).

Mudelit hinnati dialoogikorpusest võetud tegelikel inimestevahelistel dialoogidel. Korpuse analüüs annab alust oletada, et esitatud mudelit saab kasutada inimestevaheliste läbirääkimisdialoogide analüüsimiseks ja modelleerimiseks.

Arvutil on realiseeritud mudeli erijuht - vaidlus, kus $A$ suhtluseesmärk on " $B$ teeb $D$ ” ja $B$ eesmärk “ $B$ ei tee $D$ ”. Kogu mudeli rakendamine jääb aga edaspidiseks.

\section{Viidatud kirjandus}

Aller, Sven; Gerassimenko, Olga; Hennoste, Tiit; Kasterpalu, Riina; Koit, Mare; Mihkels, Krista; Laanesoo, Kirsi; Rääbis, Andriela 2014. Dialoogide pragmaatilise analüüsi tarkvara. [Software for pragmatic analysis of dialogues.] - Eesti Rakenduslingvistika Ühingu aastaraamat, 10, 23-36. http://dx.doi.org/10.5128/ERYa.1736-2563

Caelen, Jean; Xuereb, Anne 2011. Dialogue and game theory. - Corneliu Burileanu, Horia-Nicolai Teodorescu (Eds.). Proc. of the 6th Conference on Speech Technology and Human-Computer Dialogue (SpeD), Braşov, Romania, 1-10. http://dx.doi. org/10.1109/SPED.2011.5940726

Besnard, P.; Hunter, A. 2008. Elements of Argumentation. Cambridge, MA: MIT Press. http://dx.doi.org/10.7551/mitpress/9780262026437.001.0001

Chesñevar, C.; Maguitman, A.; Loui, R. 2000. Logical models of argument. - ACM Computing Surveys, 32 (4), 337-383. http://dx.doi.org/10.1145/371578.371581 
Dung, Phan Minh 1995. On the acceptability of arguments and its fundamental role in nonmonotonic reasoning, logic programming and n-person games. - Artificial Intelligence, 77 (2), 321-358. http://dx.doi.org/10.1016/0004-3702(94)00041-X

Hadjinikolis, C.; Modgil, S.; Black, E.; McBurney, P.; Luck, M. 2012. Investigating strategic considerations in persuasion dialogue games. - Frontiers in Artificial Intelligence and Applications 241: STAIRS 2012. IOS Press, 137-148. http://dx.doi. org/10.3233/978-1-61499-096-3-137

Hennoste, Tiit; Gerassimenko, Olga; Kasterpalu, Riina; Koit, Mare; Rääbis, Andriela; Strandson, Krista 2009. Suulise eesti keele korpus ja inimese suhtlus arvutiga. [Corpus of spoken Estonian and human-computer interaction.] - Eesti Rakenduslingvistika Ühingu aastaraamat, 5, 111-130. http://dx.doi.org/10.5128/ERYa5.07

Jennings, N. R.; Parsons, S.; Noriega, P.; Sierra, C. 1998. On argumentation-based negotiation. - Proc. of the International Workshop on Multi-Agent Systems, Boston, 1-7.

Koit, Mare 2012. Konversatsiooniagendi modelleerimine argumenteerimisdialoogis: suhtlus kui infoseisundite värskendamine. [Modelling of conversational agents in argumentation: Conversation as updating of information states.] - Eesti Rakenduslingvistika Ühingu aastaraamat, 8, 109-122. http://dx.doi.org/10.5128/ERYa8.07

Koit, Mare 2010. Eesti dialoogikorpus ja argumenteerimisdialoogi arvutil modelleerimine. [Estonian dialogue corpus and computer modelling of argumentation dialogue.] - Keel ja Kirjandus, 4, 241-262.

Koit, Mare; Õim, Haldur 2014a. A computational model of argumentation in agreement negotiation processes. - Argument \& Computation, 5 (2-3), 209-236. http://dx.doi. org/10.1080/19462166.2014.915233

Koit, Mare; Õim, Haldur 2014b. Modelling debates on the computer. - Joaquim Filipe, Jan Dietz, David Aveiro (Eds.). Proc. of the 6th International Conference on Knowledge Engineering and Ontoly Development (KEOD). Rome: SciTePress, 361-368. http:// dx.doi.org/10.5220/0005129303610368

Prakken, H.; Vreeswijk, G. A. W. 2002. Logics for defeasible argumentation. - D. M. Gabbay, F. Guenthner (Eds.). Handbook of Philosophical Logic, vol. 2. 2nd edition. DordrechtBoston-London: Kluwer Academic Publishers, 219-318.

Rahwan, I.; Larson, K. 2011. Logical mechanism design. - The Knowledge Engineering Review, 26 (1), 61-69. http://dx.doi.org/10.1017/So269888910000421

Rahwan, I.; Ramchurn, S. D.; Jennings, N. R.; Mcburney, P.; Parsons, S.; Sonenberg, L. 2004. Argumentation-based negotiation. - The Knowledge Engineering Review, 18 (4), 343-375. http://dx.doi.org/10.1017/So269888904000098

Stilman, B. 2011. Thought experiments in linguistic geometry. - COGNITIVE 2011: Proc. of the Third International Conference on Advanced Cognitive Technologies and Applications, 76-83.

Stilman, B.; Yakhnis, V.; Umanskiy, O. 2010. Discovering role of linguistic geometry. - Proc. of the 9th Mexican International Conference on Artificial Intelligence Conference on Advances in Soft Computing MICAI 2010, Pachuca, Mexico, Part II, 1-21. http:// dx.doi.org/10.1007/978-3-642-16773-7 1

Yuan, T.; Moore, D.; Grierson, A. 2008. A human-computer dialogue system for educational debate, a computational dialectics approach. - International Journal of Artificial Intelligence in Education, 18 (1), 3-26.

Wagner, G. 1998. Foundations of Knowledge Systems with Applications to Databases and Agents. Kluwer Academic Publishers. http://dx.doi.org/10.1007/978-1-4615-5723-4

Mare Koit (Tartu Ülikool) on uurinud dialoogi modelleerimist arvutil.

Liivi 2, 50409 Tartu, Estonia

mare.koit@ut.ee 


\section{MODELLING NEGOTIATIONS \\ ON THE COMPUTER}

\section{Mare Koit}

University of Tartu

In the paper, a model of negotiation is developed which includes a model of argument. The topic of negotiation between two participants is an action to be performed by one of them. The initial communicative goals of the participants can match or not. In the first case, they are cooperatively looking for reasons why performing (or not performing) the action is useful, pleasant, etc. In the second case, they are involved in debate. They present arguments and counter-arguments and in the end, one of them will abandon his or her initial communicative goal. An analysis of humanhuman negotiations is carried out in order to give a preliminary evaluation of the introduced model. A limited version of the model is implemented on the computer.

Keywords: negotiation, argument, dialogue model, knowledge representation, dialogue corpus, Estonian 